\title{
Aryl- and alkyl-phosphorus-containing flame retardants induced mitochondrial impairment and cell death in Chinese hamster ovary (CHO-k1) cells ${ }^{\text {茨 }}$
}

\author{
Chao Huang a, b ${ }^{\text {, Na } \text { Li }^{c} \text {, Shengwu Yuan }}{ }^{\text {a, b }}$, Xiaoya Ji ${ }^{\text {a, b }}$, Mei Ma ${ }^{\text {a, b, * }}$, Kaifeng Rao ${ }^{\text {d, }}$ \\ Zijian Wang ${ }^{\mathrm{d}}$ \\ ${ }^{a}$ Key Laboratory of Drinking Water Science and Technology, Research Center for Eco-Environmental Sciences, Chinese Academy of Sciences, 100085 Beijing, \\ China \\ ${ }^{\mathrm{b}}$ College of Resources and Environment, University of Chinese Academy of Sciences, 100049 Beijing, China \\ ${ }^{\mathrm{c}}$ Research Center for Eco-Environmental Sciences, Chinese Academy of Sciences, 100085 Beijing, China \\ d State Key Laboratory of Environmental Aquatic Chemistry, Research Center for Eco-Environmental Sciences, Chinese Academy of Sciences, 100085 Beijing, \\ China
}

\section{A R T I C L E I N F O}

\section{Article history:}

Received 18 March 2017

Received in revised form 15 June 2017

Accepted 7 July 2017

Available online 19 July 2017

\section{Keywords:}

Phosphorus-containing flame retardants

High content screening

Mitochondrial impairment

Cell death

\begin{abstract}
A B S T R A C T
Phosphorus-containing flame retardants (PFRs) are increasingly in demand worldwide as replacements for brominated flame retardants (BFRs), but insufficient available toxicological information on PFRs makes assessing their health risks challenging. Mitochondria are important targets of various environmental pollutants, and mitochondrial dysfunction may lead to many common diseases. In the present study, mitochondria impairment-related endpoints were measured by a high content screening (HCS) assay for 11 selected non-halogen PFRs in Chinese hamster ovary (CHO-k1) cells. A cluster analysis was used to categorize these PFRs into three groups according to their structural characteristics and results from the HCS assay. Two groups, containing long-chain alkyl-PFRs and all aryl-PFRs, were found to cause mitochondrial impairment but showed different mechanisms of toxicity. Due to the high correlation between cell death and mitochondrial impairment, two PFRs with different structures, trihexyl phosphate (THP) and cresyl diphenyl phosphate (CDP), were selected and compared with chlorpyrifos (CPF) to elucidate their mechanism of inducing cell death. THP (an alkyl-PFR) was found to utilize a similar pathway as CPF to induce apoptosis. However, cell death induced by CDP (an aryl-PFR) was different from classical necrosis based on experiments to discriminate among the different modes of cell death. These results confirm that mitochondria might be important targets for some PFRs and that differently structured PFRs could function via distinct mechanisms of toxicity.
\end{abstract}

() 2017 Elsevier Ltd. All rights reserved.

\section{Introduction}

Due to the increasingly rigid restrictions on the production and usage of brominated flame retardants (BFRs) by the European Union (EU) and other countries, the production and application of phosphorus-containing flame retardants (PFRs), which are regarded as suitable alternatives for BFRs, have gradually increased

\footnotetext{
This paper has been recommended for acceptance by Prof. von Hippel Frank A

* Corresponding author. Key Laboratory of Drinking Water Science and Technology, Research Center for Eco-Environmental Sciences, Chinese Academy of Sciences, Shuangqing Road 18\#, Haidian District, Beijing 100085, China.

E-mail address: mamei@rcees.ac.cn (M. Ma).
}

(Betts, 2008; Cox and Efthymiou, 2003). However, as with BFRs, most PFRs are additives and are not chemically bonded to the enduse products, which may allow them to easily diffuse into various environmental media (Rodriguez et al., 2006; van der Veen and de Boer, 2012). Additionally, some PFRs with high bio-concentration factor values have the potential to bio-accumulate in organisms (Hou et al., 2016; van der Veen and de Boer, 2012). Indeed, high concentrations of PFRs have been detected in various environmental and biotic samples in recent decades (Reemtsma et al., 2006; van der Veen and de Boer, 2012). Therefore, PFRs represent a family of chemicals that have become an emerging environmental issue. Increasingly, research has revealed that PFRs, especially chlorinated-PFRs, have the potential to be carcinogenic and 
reprotoxic (EU, 2014). Consequently, three chlorinated PFRs are now restricted by the EU Toy Safety Directive 2014/79/EU. Conversely, non-halogen PFRs are used as flame retardants in various products, and there is an increasing demand for these nonhalogen PFRs in the world market (Rakotomalala et al., 2010; Takigawa et al., 2001; van der Veen and de Boer, 2012; Zhou et al., 2008). Previous studies have shown that exposure to nonhalogen PFRs has the potential to cause neurological effects, endocrine disruptions, cardiac disorders, carcinogenic changes, and oxidative stress in different organisms (Du et al., 2015; EPA, 2007; Hausherr et al., 2014; Jin et al., 2015; Kluwe et al., 1985; Meeker and Stapleton, 2010; Yuan et al., 2016). Unfortunately, we still lack sufficient safety or toxicological information for these nonhalogen PFRs that are currently in use, even though significant numbers of people are exposed to them.

As a type of emerging environmental pollutant, PFRs are structurally similar to organophosphate pesticides (OPs). Although PFRs, like OPs, can induce significant neurotoxicity in vitro and in vivo, a growing body of research demonstrates that found PFRs have low potency compared to OPs with respect to inhibiting acetylcholinesterase (AChE) (Dishaw et al., 2011; Moser et al., 2015; Yuan et al., 2016). Meanwhile, over the last decade, OPs have been shown to exhibit multiple potential non-cholinergic mechanisms, accounting for some of the adverse consequences of OPs exposure (Terry, 2012). Recently, there is substantial evidence has suggested that mitochondria are one of the important non-cholinesterase targets of OPs (dos Santos et al., 2016; Karami-Mohajeri and Abdollahi, 2013; Yamada et al., 2017). In fact, some PFRs were found to acutely decrease the mitochondrial membrane potential $(\Delta \Psi)$ in HepG2 cells (Attene-Ramos et al., 2015; NCBI, 2012). Therefore, we hypothesize that the induction of mitochondrial dysfunction by PFRs is a potential mechanism behind the adverse consequences of PFRs. A recent study has also revealed that PFRs have the potential to induce oxidative stress, DNA damage, neurotoxicity, and cardiotoxicity (Dishaw et al., 2011; Du et al., 2015; Jin et al., 2015; Yuan et al., 2016). Most of these PFRs-induced toxic effects are more or less associated with the mitochondrial dysfunction. The impairment of mitochondria may further result in some common diseases, including cancer, diabetes, and neurodegenerative and cardiovascular diseases (Ferrari, 1996; Lin and Beal, 2006; Shaughnessy et al., 2014; Whitaker et al., 2016). Hence, there is a need for more detailed work to fully investigate the mitochondrial impairment induced by PFRs.

In addition to their role in cellular energy metabolism, mitochondria are now considered central players in cell death (Ott et al., 2007). Previous work has discerned the mechanism of mitochondria-mediated apoptosis (Jiang and Wang, 2004). However, the study of cell death was recently revitalized by the understanding that necrosis can occur in a highly regulated and genetically controlled manner (Berghe et al., 2014). Numerous examples of this process are emerging, and some of them, including parthanatos (David et al., 2009) and ferroptosis (Dixon et al., 2012), depend greatly on mitochondrial participation. Different types of programmed cell death (PCD) are initiated by specific stimuli and recruit diverse core regulators to execute cell death, which results in cells exhibiting distinct morphological and biochemical features during these processes (Xie et al., 2016). The morphological features of the cytoskeleton and mitochondria have proven to be valuable parameters for characterizing compound-induced cell death using cluster analysis (Wolpaw et al., 2011). Biochemical features, including $\Delta \Psi$, ATP level, ROS production, intracellular calcium concentration and activation of caspases, could provide further information to distinguish some types of PCD (David et al.,
2009; Dixon et al., 2012; Reed and Pellecchia, 2012; Xie et al., 2016). OPs such as chlorpyrifos (CPF) may induce cell death. Indeed, previous work has found that mitochondria-induced apoptosis was observed in CPF-treated cells (Lee et al., 2012). However, some in vitro studies suggested that the cell death induced by TOCP seemed to be distinct from apoptosis (Carlson et al., 2000). Additionally, there is more than one mechanism that could explain the toxicity of organophosphorus compounds via mitochondrial impairment (Karami-Mohajeri and Abdollahi, 2013). Therefore, the mechanisms of cell death induced by different PFRs need to be discerned.

High content screening (HCS) has been shown to be a powerful approach to assess mitochondrial impairment induced by compounds (Attene-Ramos et al., 2015; Tolosa et al., 2015; Wolpaw et al., 2011). HCS integrated with image analysis algorithms and informatics tools is able to collect quantitative data from complex biological systems. These data, containing multiple cellular parameters calculated from HCS, such as morphology and texture, have proven to be useful for characterizing cellular or organellular microstructures in recent studies (Sailem et al., 2015). Consequently, HCS has been widely used with cluster analysis in chemical biology screens to identify compounds that induce specific phenotypes, or in unbiased, general cytological profiling of compounds based on an integrated set of morphological alterations to support structure-activity relationships of chemicals (Adams et al., 2006; Tanaka et al., 2005; Wolpaw et al., 2011).

The main purpose of this study was to examine the mitochondrial impairment of the 11 selected non-halogen PFRs and identify the different possible mechanisms leading to cell death. Therefore, an HCS assay was designed and used to quantitatively analyse multi-parametric features of cellular changes in cytotoxicity, mitochondrial membrane potential and the morphologies or textures of nuclei, mitochondria and cells after PFR exposure. A cluster analysis was also used to analyse data and discern the relationships between mitochondrial toxicity and the structures of these PFRs. Chinese hamster ovary (CHO-k1) cells were chosen because these cells are traditionally used for studying mitochondrial toxicity and function (Ferrer et al., 2009; Stone and Vance, 2000). THP (an alkylPFR) and CDP (an aryl-PFR), which had high-level inducible results, were selected from two different groups, and the mechanisms of cells death induced by these compounds were further investigated.

\section{Materials and methods}

\subsection{Chemicals}

Trimethyl phosphate (TMP, 98+\%), tripropyl phosphate (TPP, 99\%), tri-n-butyl phosphate (TNBP, 99\%), tris(2-ethylhexyl) phosphate (TEHP, 97\%), N-acetyl-L-cysteine (NAC, 99+\%), dimethyl sulfoxide (DMSO), Pluronic ${ }^{\circledR}$ F-127, HEPES, Hoechst 33,342, propidium iodide (PI), and $2^{\prime}, 7^{\prime}$-dichlorofluorescin diacetate $\left(\mathrm{H}_{2} \mathrm{DCF}-\mathrm{DA}\right)$ were purchased from Sigma-Aldrich (St. Louis, MO, USA). TOCP (99+\%), tri- $m$-cresyl phosphate (TMCP, $97+\%)$, tri-p-cresyl phosphate (TPCP, 99\%), cresyl diphenyl phosphate (CDP, 97.1\%), triphenyl phosphate (TPHP, 99+\%), triethyl phosphate (TEP, 99+\%), trihexyl phosphate (THP, 95+\%), chlorpyrifos (CPF, 95+\%), and carbonyl cyanide metachlorophenylhydrazone (CCCP, 98\%) were acquired from J\&K Chemical (Shanghai, China). Tetramethylrhodamine ethyl ester (TMRE) and Fluo- $8^{\circledR}$ AM were obtained from AAT Bioquest (Sunnyvale, CA, USA). SYTOX ${ }^{\circledR}$ Green and Mito Tracker Deep ${ }^{\circledR}$ Red FM were acquired from Thermo Fisher Scientific (Waltham, MA, USA). All other chemicals were of analytical purity and were purchased from Sinopharm Chemical Reagent Co., Ltd (Shanghai, China). 


\subsection{Cell culture and exposure}

CHO-k1 cells were obtained from the Cell Culture Center, Institute of Basic Medical Sciences of the Chinese Academy of Medical Sciences and School of Basic Medicine of Peking Union Medical College, Beijing, China. Cells were cultured in Dulbecco's modified Eagle medium, Nutrient Mixture F-12 (DMEM/F-12 medium in a ratio of $1: 1$, Hyclone, Shanghai, China) with $10 \%$ defined supplemented foetal bovine serum (PAN Biotech Ltd, Aidenbach, Germany), $1 \%$ penicillin-streptomycin $(10,000 \mathrm{U} / \mathrm{ml}$, Hyclone, Logan, UT, USA), and 0.1\% amphotericin B $(2.5 \mathrm{mg} / \mathrm{mL}$, Amresco, Solon, $\mathrm{OH}$, USA). The cells were maintained at $37{ }^{\circ} \mathrm{C}$ in a $5 \% \mathrm{CO}_{2}$ atmosphere in a $\mathrm{CO}_{2}$ incubator (Panasonic, Ehime-ken, Japan), and the medium was refreshed every three or four days during subculturing (Westerink et al., 2011). Each experimental condition was assayed in triplicate wells. The stock solutions of the compounds were first prepared and serially diluted to different concentrations in DMSO. Then, all compounds were diluted in culture medium or buffer, and the final DMSO concentration in the medium was $0.5 \%(\mathrm{v} / \mathrm{v})$. During all experiments, a control culture was treated with an equivalent amount of DMSO.

\subsection{Cell viability assay}

Cell viability was measured by a Cell Counting Kit-8 (CCK-8) Cytotoxicity/Viability Assay (Beyotime Biotechnology, Haimen, China) according to the manufacturer's instructions. $\mathrm{CHO}-\mathrm{k} 1$ cells were seeded at a density of 3000 cells/well in 96-well microtiter plates (Corning, Tewksbury, MA, USA). After $24 \mathrm{~h}$ of pre-culture, cells were exposed for $24 \mathrm{~h}$ to 10 concentrations of PFRs. These compound-treated cells were washed with Tyrode's buffer (TB: $145 \mathrm{mM} \mathrm{NaCl}, 5 \mathrm{mM} \mathrm{KCl}, 10 \mathrm{mM}$ glucose, $1.5 \mathrm{mM} \mathrm{CaCl}_{2}, 1 \mathrm{mM} \mathrm{MgCl} 2$ and $10 \mathrm{mM}$ HEPES; pH adjusted to 7.4 with $\mathrm{NaOH}$ ). Next, cells in each well were incubated with $100 \mu \mathrm{l}$ of TB containing $10 \mu \mathrm{l}$ of CCK8 solution for $2 \mathrm{~h}$ at $37{ }^{\circ} \mathrm{C}$ in a humidified $5 \% \mathrm{CO}_{2}$ atmosphere. Finally, the absorbance of each well at $450 \mathrm{~nm}$ was measured by a microplate reader (M200, Tecan, Männedorf Switzerland). Cell viability was expressed as a percentage of the control without treatment. Finally, dose-response curves were fitted based on the results of the CCK- 8 assay to determine the $\mathrm{LC}_{50}$ using the fourparameter log-logistic model of the R statistical package drc (Ritz and Streibig, 2005).

\subsection{Multi-parameter high content screening assay and data analysis}

CHO-k1 cells were seeded at a density of 6000 cells/well in 96well microtiter plates (Corning). After $24 \mathrm{~h}$ of pre-culture, cells were exposed for $3 \mathrm{~h}$ to of 11 PFR at five concentrations $(1,10,50$, 100 , and $500 \mu \mathrm{M})$. Then, the cells were washed twice with TB. To detect changes in cytotoxicity and $\Delta \Psi$ and to gain insight into subcellular structure after exposing cells to these compounds, $\mathrm{CHO}-$ $\mathrm{k} 1$ cells were incubated with a fluorophore dye cocktail (diluted in TB) containing Hoechst 33,342 (stains nuclei, $2.7 \mu \mathrm{M}$ ), SYTOX ${ }^{\circledR}$ Green (stains dead cells, $20 \mathrm{nM}$ ), TMRE (changes in $\Delta \Psi, 50 \mathrm{nM}$ ), and Mito Tracker Deep ${ }^{\circledR}$ Red FM (stains mitochondria, $200 \mathrm{nM}$ ) for $45 \mathrm{~min}$ at room temperature (Bova et al., 2005; Joshi and Bakowska, 2011; Tolosa et al., 2015). An Operetta ${ }^{\mathrm{TM}}$ High Content Screening instrument with Harmony ${ }^{\mathrm{TM}}$ software version 3.5.2 (PerkinElmer, Waltham, MA, USA) and a $40 \times$ NA objective were used for imaging (4 fields per well). Then, the collected images were analysed using the image analysis modules of the Harmony ${ }^{\mathrm{TM}}$ software to obtain multiple quantitative features of the cells according to the different fluorescence signals. Because the exposure time in this assay was reduced to $3 \mathrm{~h}$, the cytotoxicity of 11 PFRs was re-assessed to ensure that each compound at the concentration selected for obtaining cellular features exhibited suitable cytotoxicity (lower than 50\%) for a cluster analysis. Cytotoxicity in the HCS assay was assessed using SYTOX $^{\circledR}$ Green to stain dead cells or by counting the cell number in every well. SYTOX ${ }^{\circledR}$ Green is an excellent green fluorescent nuclear and chromosome counterstain that cannot permeate live cells, making it a useful indicator of dead cells within a population to determine cytotoxicity or viability (Bova et al., 2005). The loss of cells was also a sensitive index reflecting the cytotoxicity of compounds in the HCS assay (Ye et al., 2014). Cytotoxicity was accounted for and calculated as follows:

$$
\begin{aligned}
& \text { Cyto }_{\text {sytoxgreen }}(\%)=100 \times \frac{N_{\text {dead }}}{N_{\text {control }}} \\
& \text { Cyto }_{\text {count }}(\%)=100 \times\left(1-\frac{N_{\text {dead }}}{N_{\text {control }}}\right)
\end{aligned}
$$

Cyto $_{\text {sytoxgreen }}$ means the cytotoxicity determined by using SYTOX $^{\circledR}$ Green to stain dead cells, $\mathrm{N}_{\text {dead }}=$ number of cells which were stained with SYTOX ${ }^{\circledR}$ Green in selected compound-treated wells, $\mathrm{N}_{\text {control }}=$ the number of cells in DMSO-treated wells.

Cyto $_{\text {count }}$ means the cytotoxicity determined by counting cell number in every well to reflect loss of cells after compound exposure. $\mathrm{N}_{\text {treat }}=$ number of cells in compound-treated wells, $\mathrm{N}_{\text {control }}=$ the number of cells in DMSO-treated wells.

In each well, 100 cells were randomly selected under the Hoechst 33,342 channel. These cells were used to obtain multiple parameters to describe nuclear mass, morphology and texture (Hoechst 33,342 channel); cell membrane integrity and cell viability (SYTOX ${ }^{\circledR}$ Green channel); mitochondrial mass, texture, and cell morphology (Mito Tracker Deep ${ }^{\circledR}$ Red FM channel); and changes in $\Delta \Psi$ (TMRE channel). Unlike in previous studies (Bova et al., 2005; Tolosa et al., 2015), the image analysis used here could quantitatively describe the compound-induced specific phenotypes in the nuclei, mitochondria, and cells. Parameters such as texture have proven to be useful for characterizing cellular or organellular microstructures in recent research (Sailem et al., 2015). More detailed annotations of all parameters are provided in the supplementary material (Appendix A. Supplementary data, Table 1). Finally, cellular features of the cells treated with the 11 PFR cells were selected for cluster analysis at the highest treatment concentration with cytotoxicity lower than 50\%. A hierarchical cluster analysis was applied to cluster the 11 PFRs according to the multiple parameters obtained from the HCS assay using the hclust function of the $\mathrm{R}$ statistical package (R Development Core Team, 2010).

\subsection{Real-time measurement of mitochondrial membrane potential in live cells}

To better characterize the kinetics of the PFR-induced reductions in $\Delta \Psi, \Delta \Psi$ values were monitored in real time with live CHO-k1 cells. The procedure was modified according to the methods of Bova et al. (2005). In brief, CHO-k1 cells were seeded at a density of 6000 cells/well in 96-well microtiter plates (Corning) to grow for $24 \mathrm{~h}$. Cells were stained with Hoechst 33,342 and TMRE as described above. TMRE is a non-fixable cationic dye that is actively pumped into and accumulates within energized mitochondria. When mitochondria become de-energized, the dye will rapidly wash out of the cell, resulting in a decrease in fluorescence intensity indicative of a loss of $\Delta \Psi$ (Bova et al., 2005). THP (100, 75, and $10 \mu \mathrm{M}), \operatorname{CDP}(500,100$, and $10 \mu \mathrm{M})$, and $\operatorname{CPF}(200,100$, and $10 \mu \mathrm{M})$ were added to cells simultaneously, and the fluorescent images were instantly recorded in live cells in real time for nearly $2 \mathrm{~h}$ using 
Table 1

OPFRs selected for the study of mitochondrial impairment.

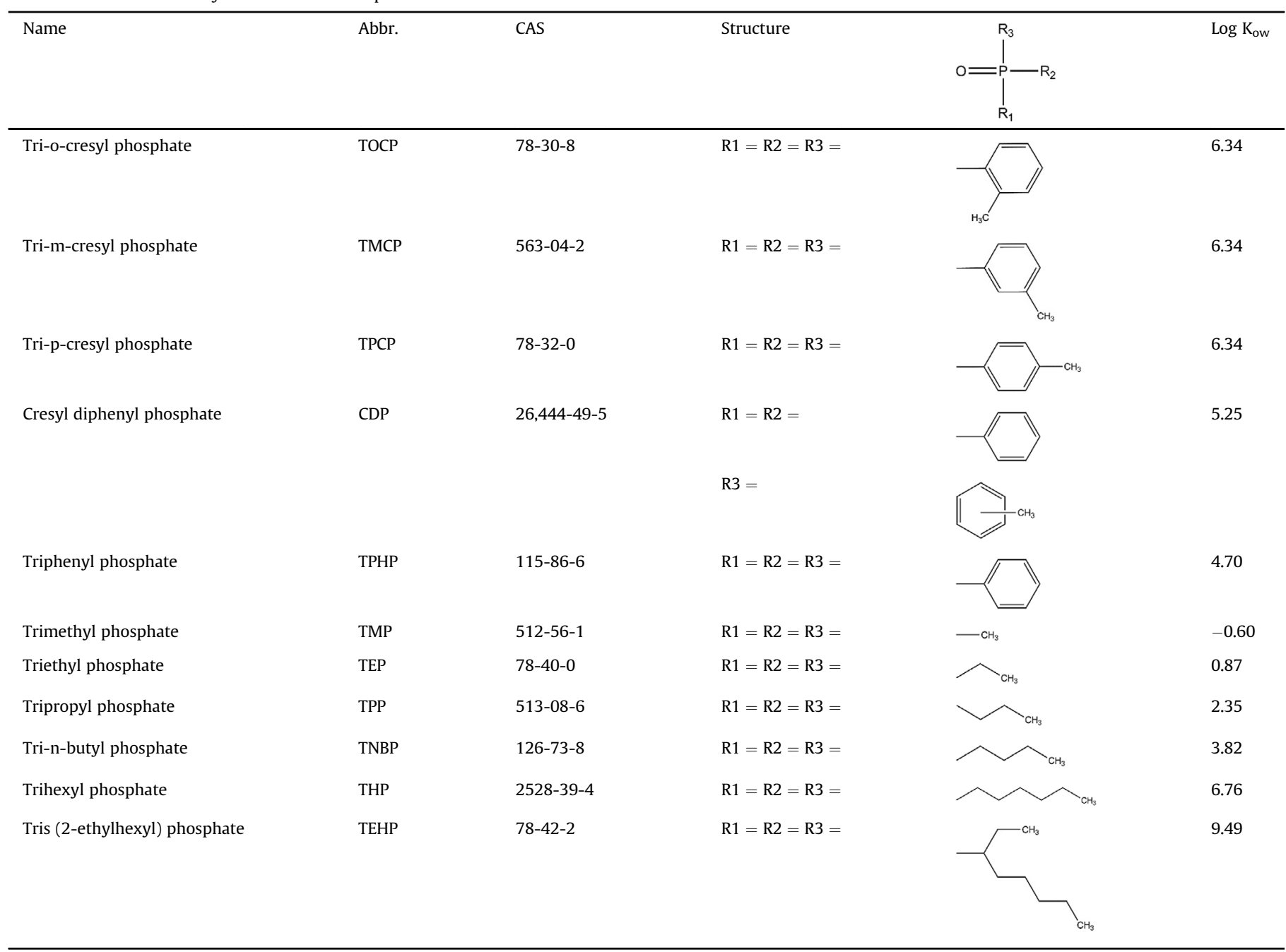

Log $\mathrm{K}_{\mathrm{ow}}$ have been estimated using EPI Suite software with KOWWIN v1.67 models.

the Operetta ${ }^{\mathrm{TM}}$ High Content Screening instrument. CCCP $(100 \mu \mathrm{M})$, which potently uncouples oxidative phosphorylation in mitochondria, was added to cells and used as a positive control.

\subsection{Biochemical features to discriminate among different cell death modes}

The appearance of phosphatidylserine (PS) residues (normally hidden within the plasma membrane) on the surface of the cell is an early event in apoptosis. Annexin- $\mathrm{V}$ has a strong, $\mathrm{Ca}^{2+}$-dependent affinity for PS and therefore can be used as a probe for detecting early apoptosis (Darzynkiewicz et al., 1997). The analysis of Annexin-V binding was performed with an Annexin-V FITC Apoptosis Detection Kit (Dojindo, Tokyo, Japan) according to the manufacturer's protocol. In brief, CHO-k1 cells were seeded at a density of 60,000 cells/well in 12-well cell culture plates (Corning). After $24 \mathrm{~h}$ of pre-culture, cells were treated with $\operatorname{THP}(75,100 \mu \mathrm{M})$, CDP $(200,500 \mu \mathrm{M})$, and CPF $(100,200 \mu \mathrm{M})$ for $3 \mathrm{~h}$. Treated cells were harvested and stained with Hoechst 33,342 $(2.7 \mu \mathrm{M})$, PI $(2.2 \mu \mathrm{M})$ and FITC-labelled Annexin-V for 20 min. The stained cells were deposited onto slides, and then these slides were mounted and observed under the $20 \times$ NA objective of an Operetta ${ }^{\mathrm{TM}}$ High Content Screening instrument with the Harmony ${ }^{\mathrm{TM}}$ software.
Image analysis was used to determine cell area under the Hoechst 33,342 channel and to calculate the labelled Annexin-V and PI intensity in each cell area.

The induction of caspases and changes in the level and intracellular concentration of ATP are different in different types of PCD (Xie et al., 2016). Therefore, three bioassays were further conducted to determine these biochemical features in CHO-k1 cells. All these assays were performed at the same cell density and using the same concentration of each compound. In brief, cells were seeded at a density of 6000 cells/well in 96-well microtiter plates (Corning). After $24 \mathrm{~h}$ of pre-culture, cells were exposed for $3 \mathrm{~h}$ to five concentrations of THP $(1,10,50,75,100 \mu \mathrm{M}), \operatorname{CDP}(1,10,100,200$, $500 \mu \mathrm{M})$, and $\operatorname{CPF}(1,10,50,100,200 \mu \mathrm{M})$. Then, various methods were used to determine these biochemical features.

Apoptosis is a highly regulated mechanism of cell death, which converges on caspase activation (Jiang and Wang, 2004). The induction of caspase-3/7 and 9 activities by THP, CDP, and CPF was determined using the Promega (Madison, WI, USA) Caspase-Glo ${ }^{\circledR} 3 /$ 7 Assay Kit and Caspase-Glo ${ }^{\mathbb{B}}$ 3/7 Assay Kit and was measured according to the manufacturer's protocol. In brief, Caspase-Glo ${ }^{\circledR}$ reagent was added to compound-treated cells, and cells were incubated for $45 \mathrm{~min}$ at room temperature. Luminescence intensity was detected using a microplate reader (M200). The luminescence 
intensity was normalized to the protein concentration in each well.

Some types of PCD, including apoptosis and necroptosis, could elevate intracellular calcium concentrations (Nomura et al., 2014; Rasola and Bernardi, 2011). To determine changes in cytosolic free calcium concentrations after exposing cells to the compounds, cells were washed twice with TB and stained with $4 \mu \mathrm{M}$ Fluo-8 AM (diluted in TB) containing Pluronic ${ }^{\mathbb{B}}$ F-127 $(0.02 \%$, W/V) by incubation for $30 \mathrm{~min}$ at $37{ }^{\circ} \mathrm{C}$ in a dark and humidified $5 \% \mathrm{CO}_{2}$ atmosphere. Then, this dye solution was replaced with TB containing $2 \mathrm{mM}$ probenecid. Each well in the 96-well microtiter plate was observed using the $20 \times$ NA objective of the Operetta ${ }^{\text {TM }}$ High Content Screening instrument with Harmony ${ }^{\mathrm{TM}}$ software. Image analysis was used to determine the cell area according to Hoechst 33,342 and to calculate the mean Fluo- 8 intensity in each cell area.

Whether cells activate apoptosis or succumb to necrosis highly depends on the residual intracellular ATP level (Rasola and Bernardi, 2011). In this study, the cellular ATP level was assessed by the PhosphoWorks ${ }^{\mathrm{TM}}$ Luminometric ATP Assay Kit (AAT Bioquest) according to the manufacturer's protocol. In brief, the ATP assay solution was added into compound-treated cells, and cells were incubated for $20 \mathrm{~min}$ at room temperature. Luminescence intensity was detected using a microplate reader (M200). The value of the luminescence intensity in each well was normalized to the protein concentration, which was measured using the Enhanced BCA Protein Assay Kit (Beyotime Biotechnology).

\subsection{Measurement of intracellular ROS}

ROS production has been implicated in various forms of cell death (Reed and Pellecchia, 2012). To monitor intracellular ROS production, fluorescent DCF, which is converted from nonfluorescent $\mathrm{H}_{2}$ DCF by ROS, was used to measure ROS production. The procedure for detecting intracellular ROS was modified according to the method of Wang and Joseph (1999). In brief, CHO-k1 cells were seeded at a density of 6000 cells/well in 96-well microtiter plates (Corning) to grow for $24 \mathrm{~h}$. First, cells were washed twice with TB and loaded with $5 \mu \mathrm{M} \mathrm{H}_{2} \mathrm{DCF}$ (diluted in TB) by incubation for $45 \mathrm{~min}$ at $37{ }^{\circ} \mathrm{C}$ in a dark and humidified $5 \% \mathrm{CO}_{2}$ atmosphere. The cells were then washed again and exposed for $3 \mathrm{~h}$ to five concentrations of THP $(1,10,50,75,100 \mu \mathrm{M}), \operatorname{CDP}(1,10,100$, $200,500 \mu \mathrm{M})$, and $\mathrm{CPF}(1,10,50,100,200 \mu \mathrm{M})$ in a dark and humidified $5 \% \mathrm{CO}_{2}$ atmosphere. Finally, the induction of intracellular ROS production in cells was measured directly using a microplate reader (M200). The fluorescence intensity in each well was normalized to the protein concentration, which was measured using the Enhanced BCA Protein Assay Kit (Beyotime Biotechnology).

\subsection{Using NAC to inhibit intracellular ROS production}

To investigate the role of ROS in the induction of cell death, NAC was used as a ROS scavenger to inhibit intracellular ROS production and reduce the effectiveness of ROS-mediated cell death (Sun, 2010). A stock solution of NAC (100 mM) was prepared in PBS. The final concentration of NAC as the ROS scavenger was $2 \mathrm{mM}$ in the cell culture medium. Cytotoxicity changes after NAC treatment and co-exposure to the tested compounds (THP, CDP and CPF) for $3 \mathrm{~h}$ were measured using a CCK- 8 cytotoxicity assay. Changes in the induction of intracellular caspase $3 / 7$ by the tested compounds after NAC treatment were also measured using the method described above.

\subsection{Statistical analysis}

Each measurement was performed in single cells, and the values for the same treatment (e.g., triplicate wells) were averaged and then normalized to the average value of the solvent-treated cells. Each experimental condition for each method was repeated at least three times in three independent cell preparations. The statistical data analysis was performed using an ANOVA followed by Bonferroni's test from the agricolae package (version 1.2-4). A $p$ value below 0.05 was considered statistically significant. Most of the presented figures were produced using the ggplot2 package (Wickham, 2016).

\section{Results}

\subsection{Cytotoxic effects of PFRs in CHO-k1 cells}

In this study, 11 selected PFRs were first analysed with respect to their potency to inhibit cell viability in CHO-k1 cells. A brief summary of the information on all the tested PFRs is shown in Table 1. All tested PFRs except for TMP, TEP, and TEHP significantly inhibited cell viability in a dose-dependent manner (Fig. 1), and their halfmaximal inhibiting concentrations $\left(\mathrm{LC}_{50}\right)$ are presented in the legend of Fig. 1. All aryl-PFRs exhibited similar cytotoxic effects in CHO-k1 cells, and their $\mathrm{LC}_{50}$ values ranged from 74 to $92 \mu \mathrm{M}$. THP, an alkyl-PFR, had the lowest $\mathrm{LC}_{50}(58 \mu \mathrm{M})$ of all the PFRs, but TMP and TEP, both of which have a short alkyl chain, could not inhibit cell viability at their highest concentration. The LogKow values of the PFRs seemed to be related to their $\mathrm{LC}_{50}$ values, especially for the alkyl-PFRs. A counter-example is TEHP, which had the highest LogKow value but relatively low cytotoxicity.

\subsection{A multi-parametric assessment of PFR-induced toxicity was conducted regarding the effects on nuclei, mitochondria, and cells}

Fig. 2 shows the $\Delta \Psi$ values of three types of alkyl-PFRs (TNBP,
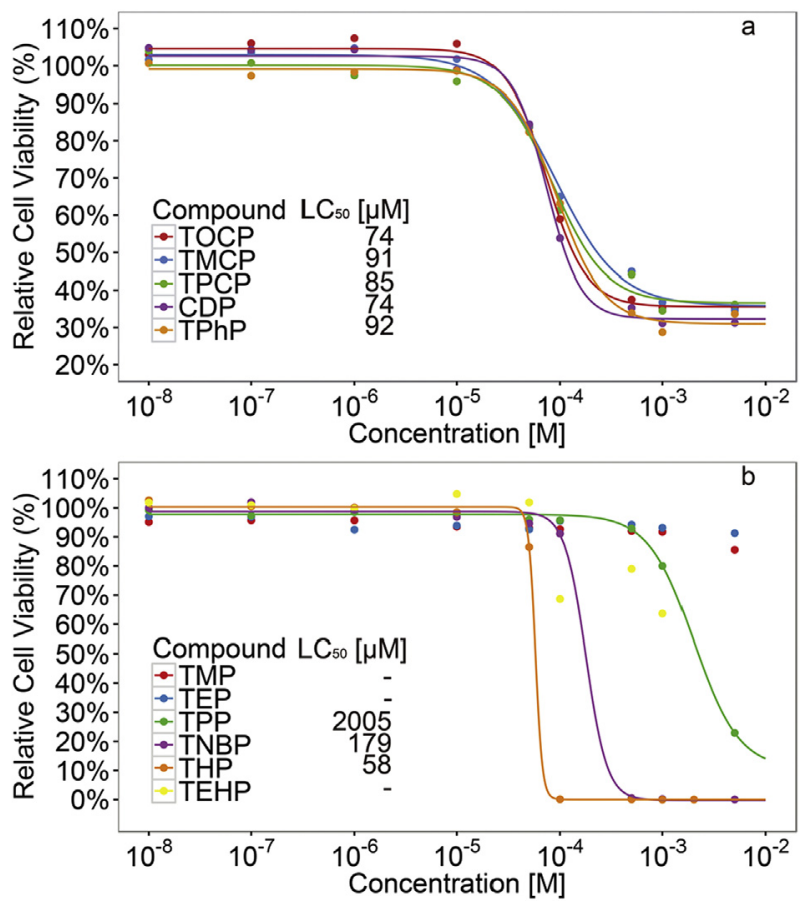

Fig. 1. The dose-response curves illustrated cytotoxic effects of PFRs on CHO-k1 cells and fitted with log-logistic model. The CHO-k1 cells were exposed to a range of concentrations of (a) aryl-OPFRs and (b) alkyl-OPFRs for $24 \mathrm{~h}$, and cell viability was measured by CCK- 8 method. The values presented are the mean of at least three independent experiments. The $\mathrm{LC}_{50}$ of each compound is shown in the legend. 

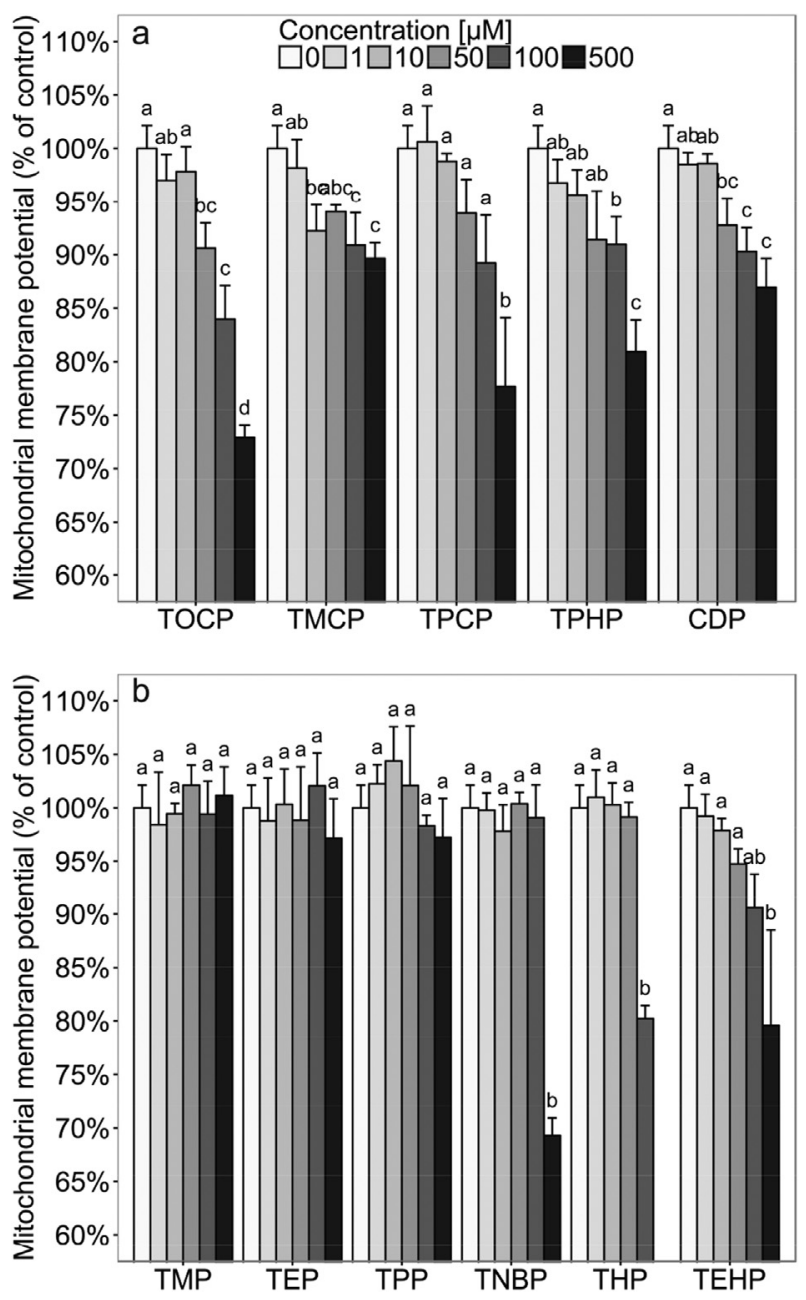

Fig. 2. Effects of test compounds on mitochondrial membrane potential. The $\mathrm{CHO}-\mathrm{k} 1$ cells were exposed to a range of concentrations of (a) aryl-OPFRs and (b) alkyl-OPFRs for $3 \mathrm{~h}$, and mitochondrial membrane potential was detected by staining with TMRE. The values presented are the mean \pm SEM of at least three independent experiments. A significant difference among the groups of $p<0.05$ (ANOVA) is indicated by differences in the letters.

THP, and TEHP), and all aryl-PFRs were found to significantly decrease $\Delta \Psi$ in a dose-dependent manner. Additionally, all these compounds had relatively high LogKow values, as shown in Table 1. However, TMP, TEP, and TPP, which have lower LogKow values ( $<2.5)$, lacked the ability to decrease $\Delta \Psi$ in $\mathrm{CHO}-\mathrm{k} 1$ cells. This result indicated that the ability of selected PFRs to decrease $\Delta \Psi$ might be associated with their hydrophobicity and could affect their cytotoxicity. Fig. 3 indicates that all aryl-PFRs and TEHP can increase the mitochondrial mass in a dose-dependent manner, but TNBP at a high concentration decreased the mitochondrial mass. There was no significant difference from the negative control group in cellular mitochondrial mass between cells treated with TMP, TEP, TPP, or THP $(p>0.05)$.

Cellular features for clustering were obtained at the concentration where the cytotoxicity of each compound was lower than $50 \%$ (Table 2). These concentrations were: $500 \mu \mathrm{M}$ for TMCP, TOCP, TPCP, CDP, TMP, TEP, TPP, TNBP, and TEHP, and $100 \mu \mathrm{M}$ for THP. The results of the hierarchical cluster analysis showed that the 11 selected compounds can be divided into 3 groups (Fig. 4). The first group contained TMP, TEP, and TPP, which have relatively short straight-chain alkyl groups. The control group (only DMSO-treated) also clustered with this group, which indicates that these 3 PFRs
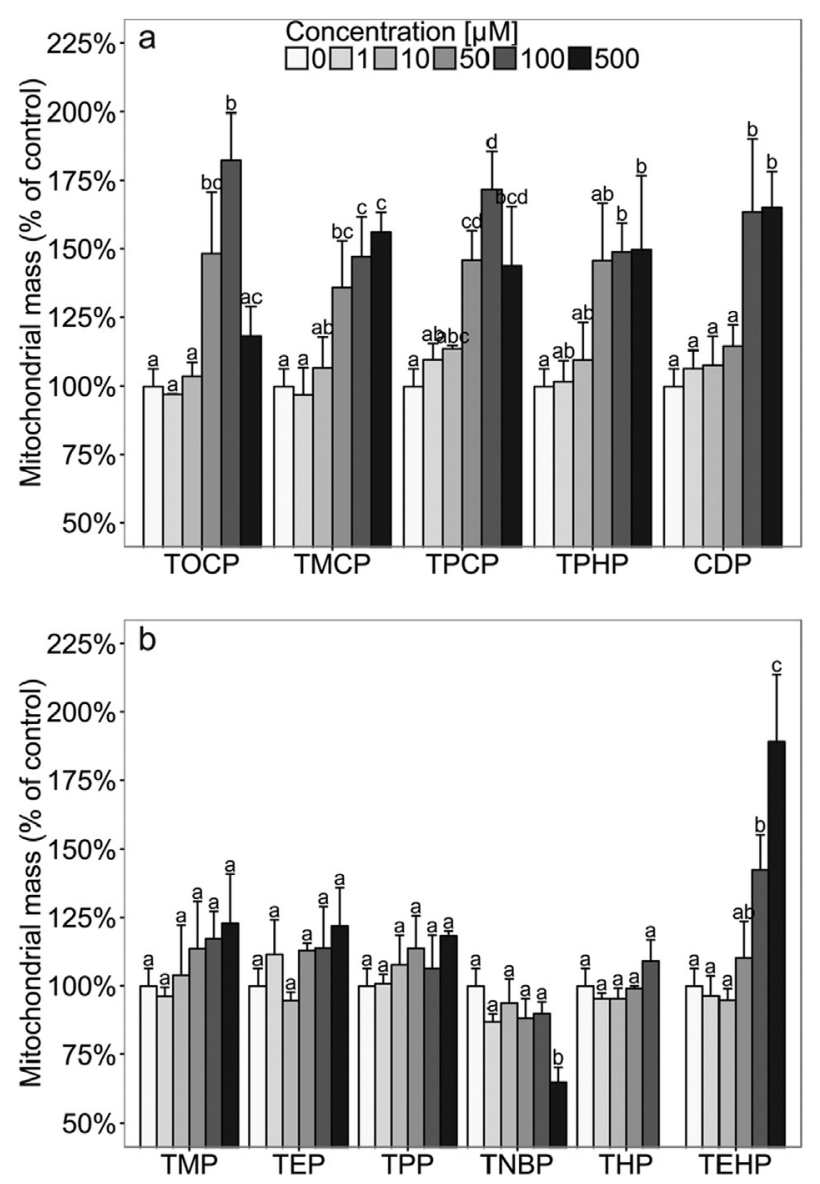

Fig. 3. Effects of test compounds on mitochondrial mass. The CHO-k1 cells were exposed to a range of concentrations of (a) aryl-OPFRs and (b) alkyl-OPFRs for $3 \mathrm{~h}$, and mitochondrial mass was detected by staining with Mito Tracker Deep ${ }^{\circledR}$ Red FM. The values presented are the mean \pm SEM of at least three independent experiments. A significant difference among the groups of $p<0.05$ (ANOVA) is indicated by differences in the letters.

Table 2

Cytotoxicity of compounds for clustering at selected concentration.

\begin{tabular}{llll}
\hline Compound & Concentration $(\mu \mathrm{M})$ & Cyto $_{\text {count }}(\%)$ & Cyto $_{\text {sytoxgreen }}(\%)$ \\
\hline TOCP & 500 & 40 & 6 \\
TMCP & 500 & 34 & 3 \\
TPCP & 500 & 35 & 19 \\
CDP & 500 & 26 & 4 \\
TPhP & 500 & 23 & 0 \\
TMP & 500 & 7 & 0 \\
TEP & 500 & 8 & 0 \\
TPP & 500 & -1 & 0 \\
TnBP & 500 & 23 & 17 \\
THP & 100 & 30 & 9 \\
TEHP & 500 & 41 & 43 \\
\hline
\end{tabular}

Cyto $_{\text {count }}$ the cytotoxicity determined by counting cell number in every well to

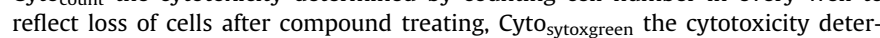
mined by using SYTOX ${ }^{\circledR}$ Green to stain dead cells.

have little effect on cells and mitochondria. Although PFRs containing aryl or long alkyl substituent groups have a similar effect on $\Delta \Psi$ (Fig. 2), the cluster analysis successfully divided these PFRs into two groups according to their structure. All 5 aryl-PFRs, including TOCP, TMCP, TPCP, CDP, and TPHP, clustered into the second group. The third group contained THP, TEHP, and TNBP, which have long alkyl substituent groups. The distinct multiple parameters that 


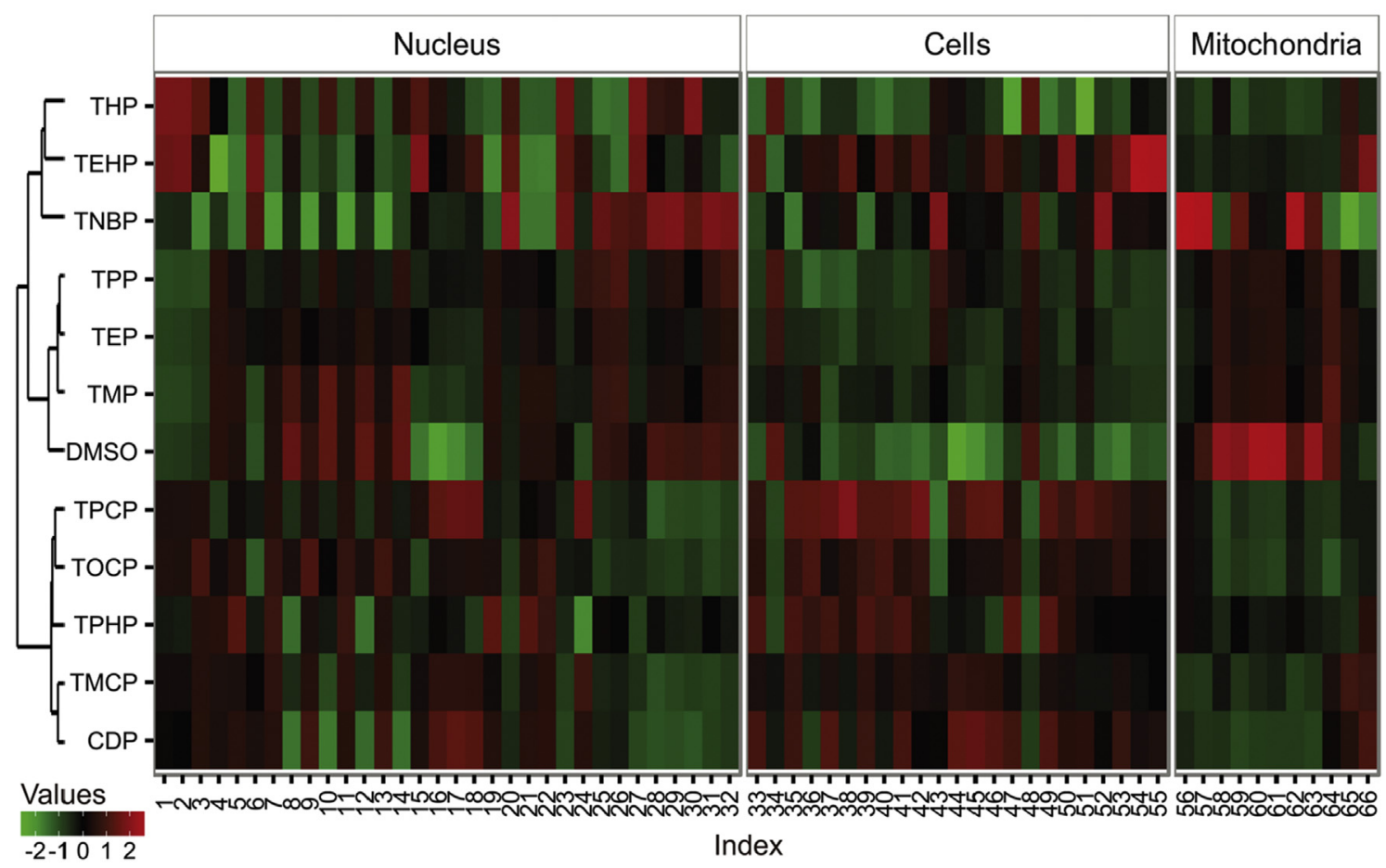

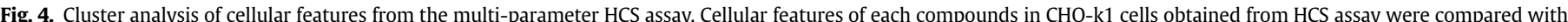

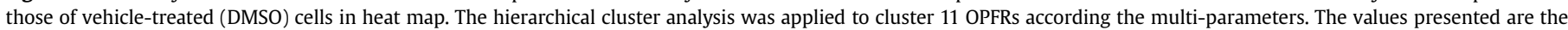

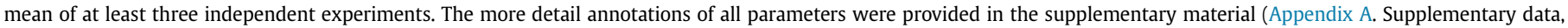
Table 1).

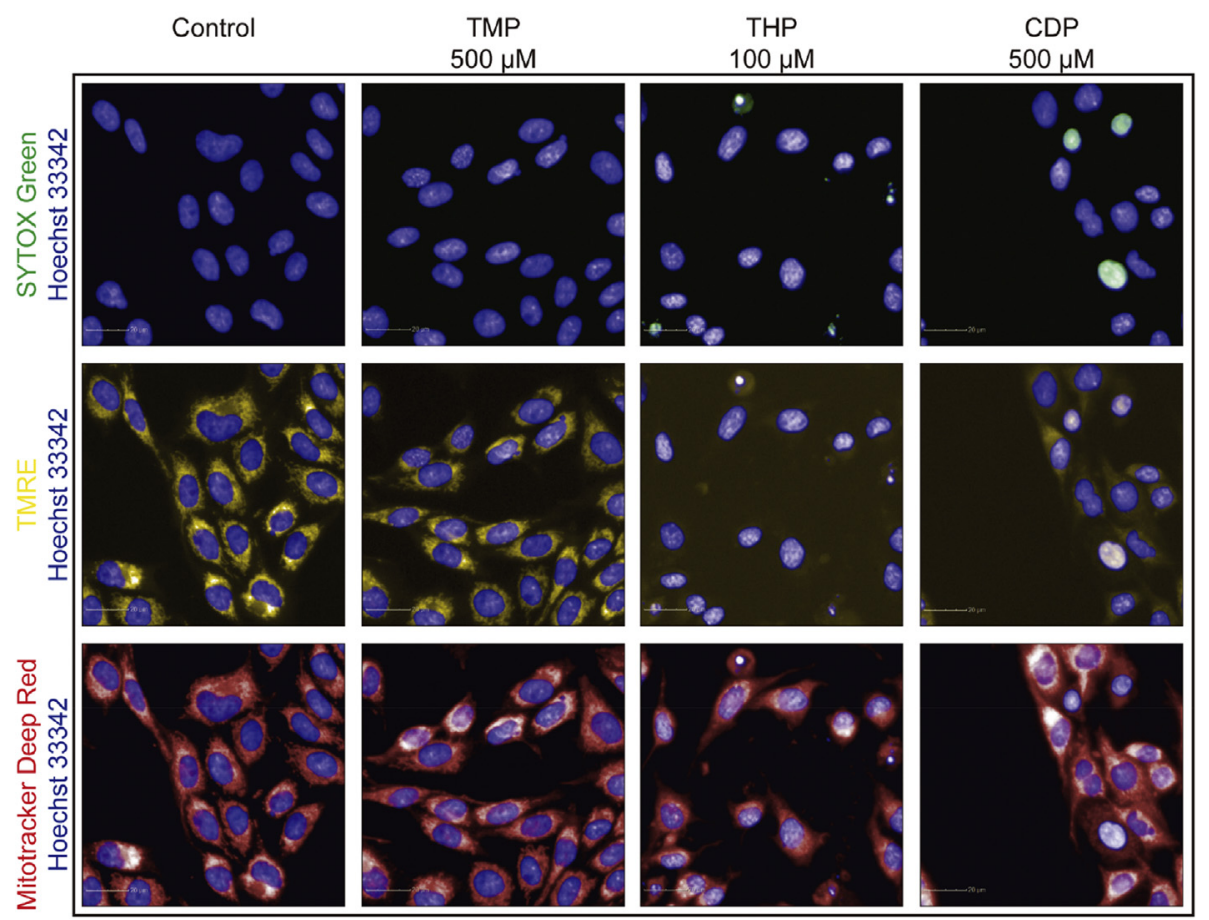

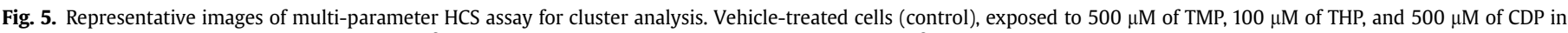

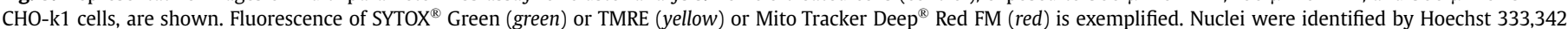

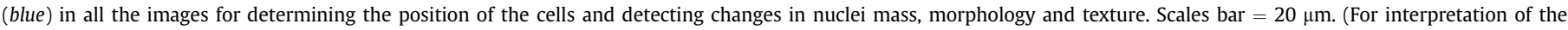
references to colour in this figure legend, the reader is referred to the web version of this article.)

describe the effects of the two classes of PFRs on cells are: 1) the area of the nuclei, 2) the texture of the nuclei, 3) the morphology of cell, and 4) the mitochondrial mass. The fluorescence images of different treated cells further confirmed these results (Fig. 5). The 
long alkyl-PFRs led to smaller and more condensed nuclei than the aryl-PFRs. Apoptotic bodies were also observed in THP-treated cells. Most PFRs could cause mitochondrial impairment and had significant cytotoxicity in the HCS assay; however, the cell death induced by aryl-PFRs and alkyl-PFRs showed distinct features. According to the results, THP (alkyl-PFRs) and CDP (aryl-PFRs) with high-level inducible results were selected as the representative molecules for aryl- and alkyl-PFRs to conduct further research into discerning the possible mechanisms of mitochondrial impairment and cell death, respectively. An organophosphorus pesticide, CPF, was also assessed in our study, and its effects were compared with THP and CDP.

\subsection{Monitoring the kinetics of THP, CDP, and CPF-induced decreases in mitochondrial membrane potential}

The reductions of $\Delta \Psi$ in response to short-term exposure to THP and CDP were obvious, which suggests that both compounds induced a fairly fast decrease in $\Delta \Psi$. Therefore, real time monitoring of THP-, CDP-, and CPF-induced changes to $\Delta \Psi$ in CHO-k1 cells was conducted to obtain the kinetics of the compoundinduced reductions in $\Delta \Psi$. THP $(100 \mu \mathrm{M})$, CDP $(500 \mu \mathrm{M})$ and CPF $(200 \mu \mathrm{M})$ also resulted in relatively rapid and pronounced reductions in $\Delta \Psi$, which indicated that mitochondria are one of the first targets influenced by these compounds (Fig. 6).

\subsection{Biochemical features of cell death induced by THP, CDP, and CPF}

Cell death was first measured by detecting PS expression and membrane permeability. When cells were exposed to the compounds for $3 \mathrm{~h}$, THP, CDP and CPF significantly increased the proportions of cells in Q2 (early apoptosis), Q3 (cell fragments from necrosis) and Q4 (necrosis or late apoptosis) (Fig. 7a). THP and CPF at high concentrations could also significantly elevate intracellular calcium concentrations and decrease ATP levels (Fig. 7b and c). However, when cells were treated with a high concentration of CDP $(500 \mu \mathrm{M})$, there was no difference for either index between CDPtreated and control cells (Fig. 7b and c). As shown in Fig. 8a and $\mathrm{b}$, exposure to THP and CPF for $3 \mathrm{~h}$ induced caspase- 9 and caspase $3 / 7$ in a concentration-dependent manner. As with intracellular calcium concentrations and ATP levels, CDP treatment could also not produce caspase 9 or caspase 3/7, even at high concentrations (Fig. 8a and b).

\subsection{Involvement of reactive oxygen species in $T H P, C D P$, and $C P F-$ induced cell death}

Fig. $7 d$ indicates that $\mathrm{THP}, \mathrm{CDP}$, and $\mathrm{CPF}$ all produced a concentration-dependent increase in DCF fluorescence intensity relative to the control. This result indicated that ROS were produced in treated cells. All compounds exhibited significant cytotoxicity in the CCK- 8 assay, but combined exposure to an individual compound and $2 \mathrm{mM}$ NAC inhibited the cytotoxicity of the test compounds to a certain degree at different concentrations (Fig. 9). Additionally, 2 mM NAC used as an ROS scavenger could also inhibit the induction of caspase 3/7 that was elicited by THP (Fig. 8c).

\section{Discussion}

Mitochondria play a central role in maintaining cell and organ function and are involved in several key pathways when cells respond to environmental stressors (Meyer et al., 2013). Recently, increasing evidence has supported that mitochondrial dysfunction and altered organelle regulation are related to many common diseases, including cancers, neurodegenerative diseases, and
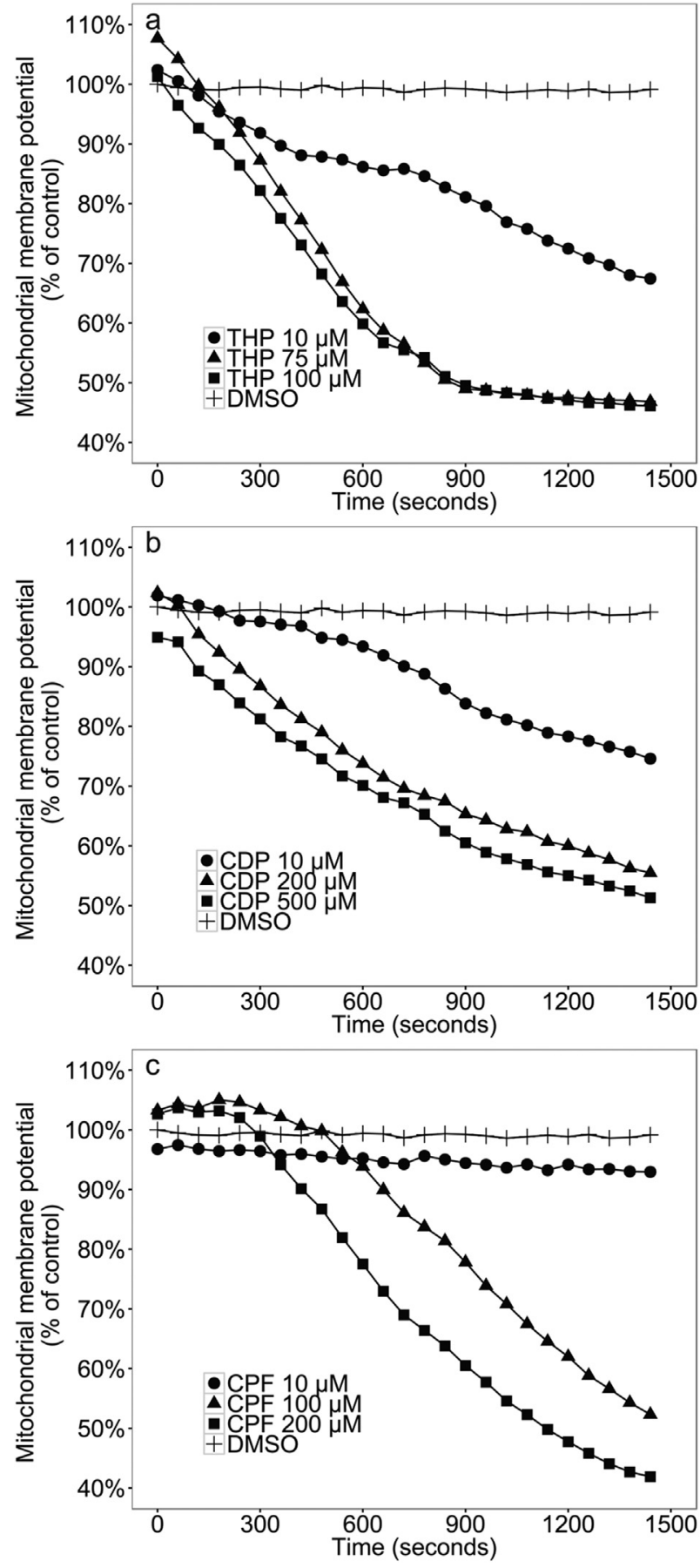

Fig. 6. Monitoring the kinetics of THP, CDP, and CPF-induced drop of $\Delta \Psi$ in real time with live cells. The CHO-k1 cells were loaded with TMRE, firstly. Then, THP (a), CDP (b), and CPF (c), as well as DMSO were applied to the cells and their images were collected as fast as possible for almost $2 \mathrm{~h}$. A drop in $\Delta \Psi$ was calculated according the TMRE channel. The values presented are the mean of at least three independent experiments.

diabetes (Shaughnessy et al., 2014; Whitaker et al., 2016). A much smaller but growing body of literature also indicates that numerous environmental pollutants can target mitochondria and cause some specific diseases (Meyer et al., 2013). PFRs are structurally similar to OPs. Some evidence has indicated that most PFRs have a lower ability to influence the function of AChE than OPs do (Moser et al., 2015; Yuan et al., 2016), but PFRs, like OPs, can cause significant mitochondrial impairment (Attene-Ramos et al., 2015; Lee et al., 

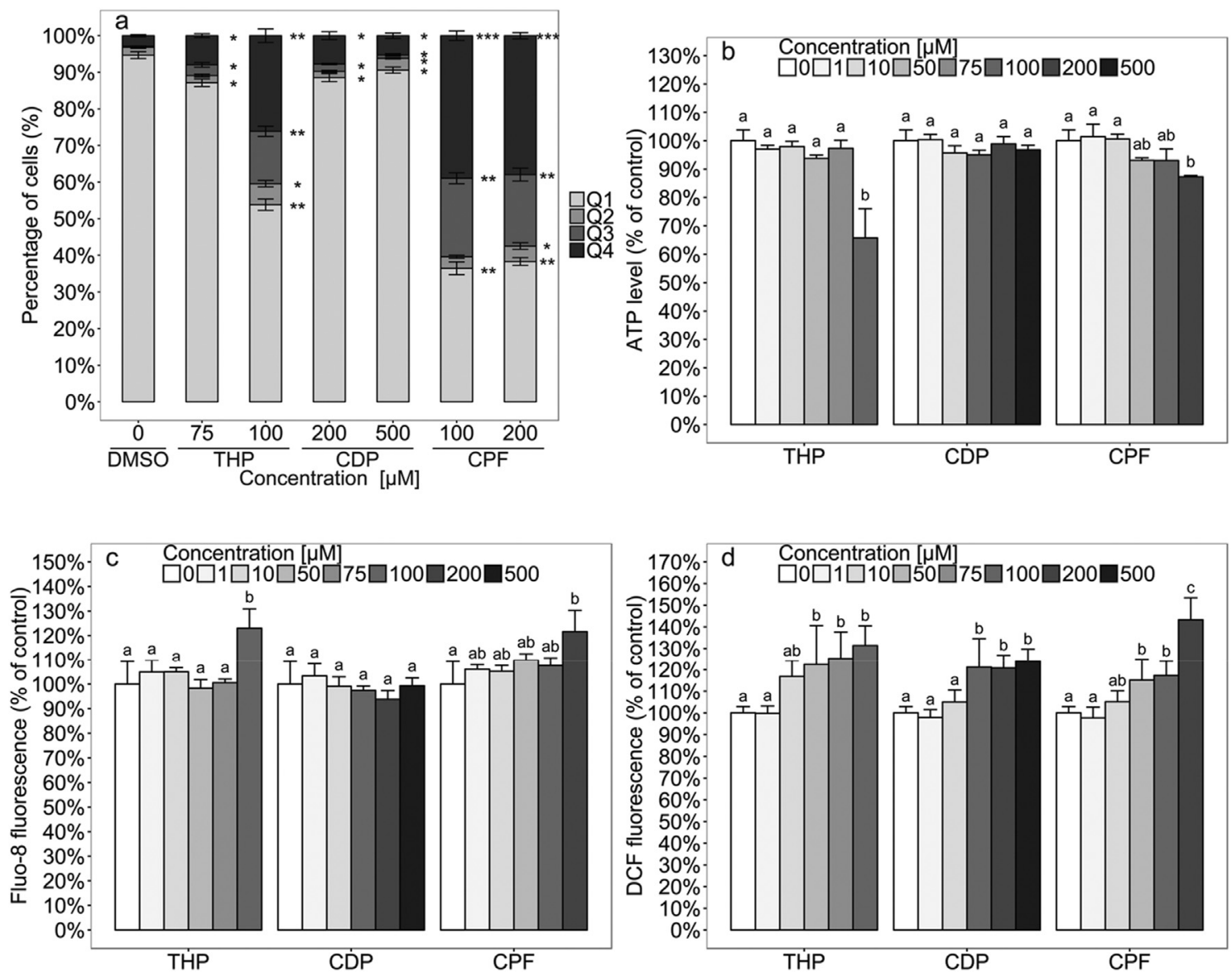

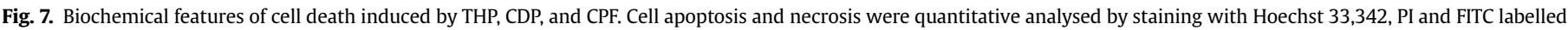

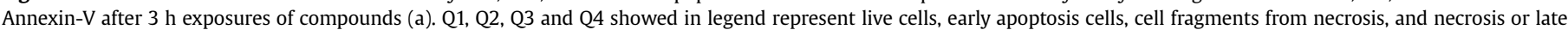

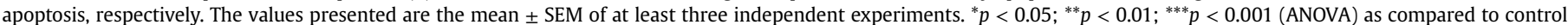

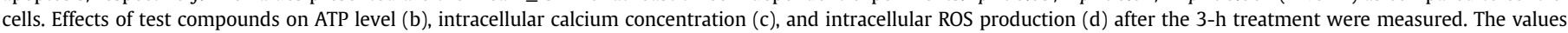

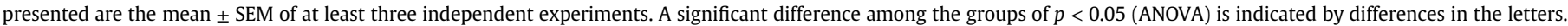

2012; NCBI, 2012). Therefore, mitochondria may be a potential target for some PFRs. Although PFRs have been increasingly used to cater to the rigid demands of flame retardants, there is a lack of sufficient toxicity and health data available for PFRs, which can easily release into the surrounding environments. In this study, we hypothesized that mitochondrial dysfunction induction by nonhalogen PFRs could be a potential mechanism to explain the adverse consequences of these compounds.

Two classes (containing aryl or alkyl substituent groups) of nonhalogen PFRs were selected as our research subject. The $\mathrm{LC}_{50}$ of the tested PFRs was assessed, and the $\mathrm{LC}_{50}$ of all PFRs except TEHP correlated with the LogKow values. In concordance, it has been shown that aryl-PFRs with high LogKow values cause acute toxicity in zebrafish embryos (Du et al., 2015). Although TEHP had the highest LogKow value (9.49) of all the PFRs tested, the cytotoxicity of TEHP was relatively low. TEHP has a low acute toxicity for mammals (NCBI, 2016a), and the cytotoxicity of this compound is inactive or inconclusive in most qHTS cytotoxicity assays from Tox21 (NCBI, 2016b). Based on Richard Horobin's QSAR decision rules (Horobin et al., 2007), it is suspected that the extremely high LogKow values of TEHP result in this compound having difficulty penetrating cell membranes.

The outcome of the multi-parameter HCS assay indicated that all PFRs except TMP, TEP, and TPP caused significant damage to mitochondria as indicated by a reduction in $\Delta \Psi$ and changes in mitochondrial mass (Fig. 4). The PFRs that reduced $\Delta \Psi$ shared high
LogKow values (>3.8). Traditionally, lipophilic cations are regarded as the most common structural type of compounds that accumulates in the mitochondrial matrix (Wallace and Starkov, 2003). However, electrically neutral esters with high LogKow values can be converted to weak acids by cellular esterases, and then these lipophilic acids are suspected to be retained in mitochondria (Horobin et al., 2007). Because PFRs are one type of ester, the hydrophobicity of PFRs was believed to help them target and undermine the function of mitochondria. Similar effects were also observed in mitochondrial membrane potential assays of Tox21 (Attene-Ramos et al., 2015), in which compounds with longer side chains have been shown to be more potent than those with shorter side chains. In general our results indicated that the hydrophobicity of PFRs can influence the ability of these compounds to induce mitochondrial impairment. Additionally, because previous studies have suggested mitochondrial impairment, such as disrupting $\Delta \Psi$, can lead to opening of the mitochondrial permeability transition pore (PTP) and eventually to cell death (Tirmenstein et al., 2002), mitochondrial-mediated cytotoxic effects (Nakagawa and Moldeus, 1998) are also suspected to exist for some PFRs.

The cluster analysis results revealed that the toxicity of the arylPFRs and long-chain alkyl-PFRs seemed to depend on the different mechanisms used. Increasing research has shown the power of HCS to probe the toxicity mechanisms of compounds (Hirsch et al., 2017; Tolosa et al., 2015; Wolpaw et al., 2011). In this study, the cluster analysis successfully distinguished aryl-PFRs and long chain 

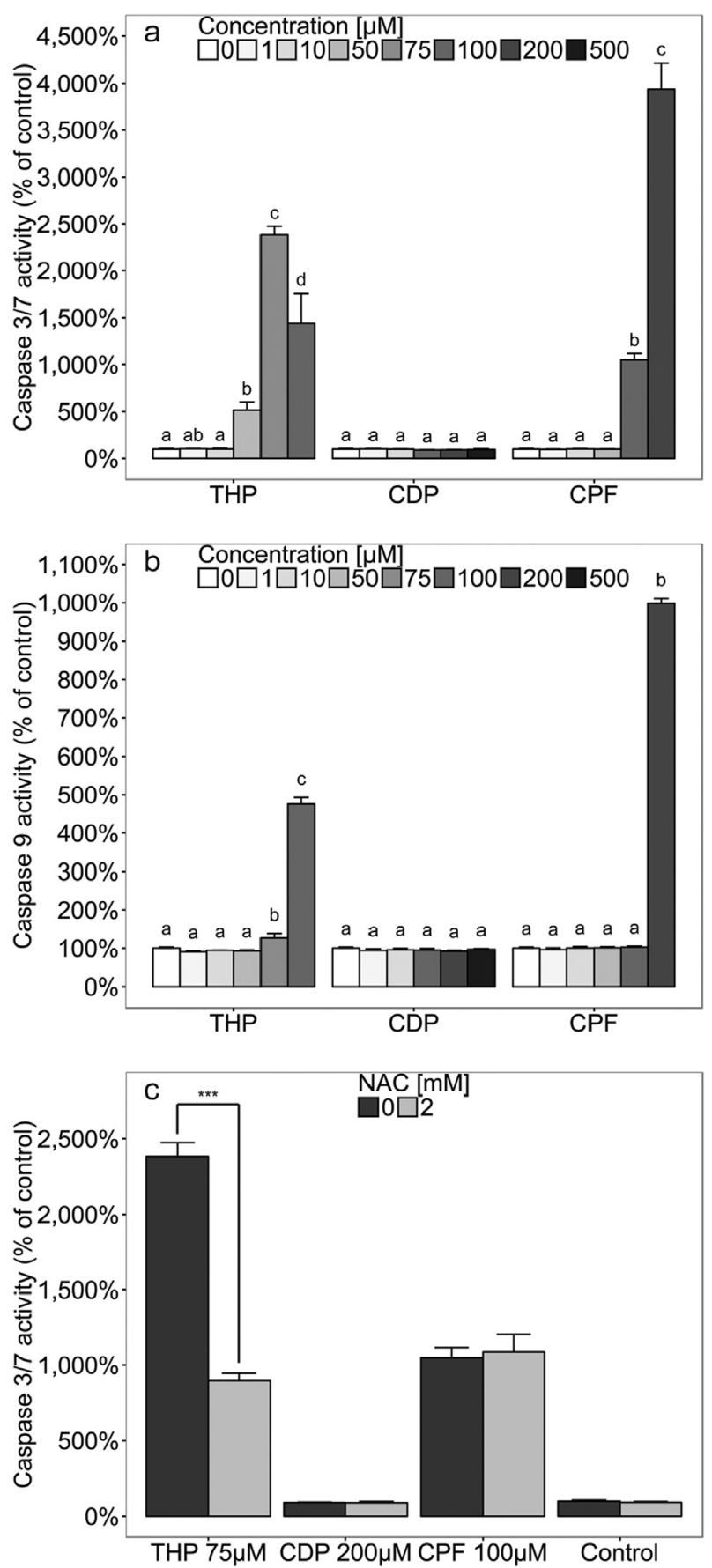

Fig. 8. The induction of caspase activities by THP, CDP, and CPF. CHO-k1 cells were exposed to a range of concentration of PFRs for $3 \mathrm{~h}$, and caspase $3 / 7$ (a) and 9 (b) activity were measured. The values presented are the mean \pm SEM of at least three independent experiments. A significant difference among the groups of $p<0.05$ (ANOVA) is indicated by differences in the letters. NAC were used as ROS scavenger to inhibit Caspase 3/7 activity (c). The values presented are the mean \pm SEM of at least three independent experiments. ${ }^{*} p<0.05$; ${ }^{* *} p<0.01$; ${ }^{* * *} p<0.001$ (ANOVA) as compared to cells without NAC treatment.

alkyl-PFRs based on the quantitative cellular or organellular features obtained from HCS. These features of the nucleus, mitochondria and cells were good indicators for discerning the mechanism of cell death (Bova et al., 2005; Tolosa et al., 2015; Wolpaw et al., 2011). Fig. 5 further indicates long chain alkyl-PFRtreated cells undergoing apoptosis showed characteristic morphological features. Although dead cells were also found
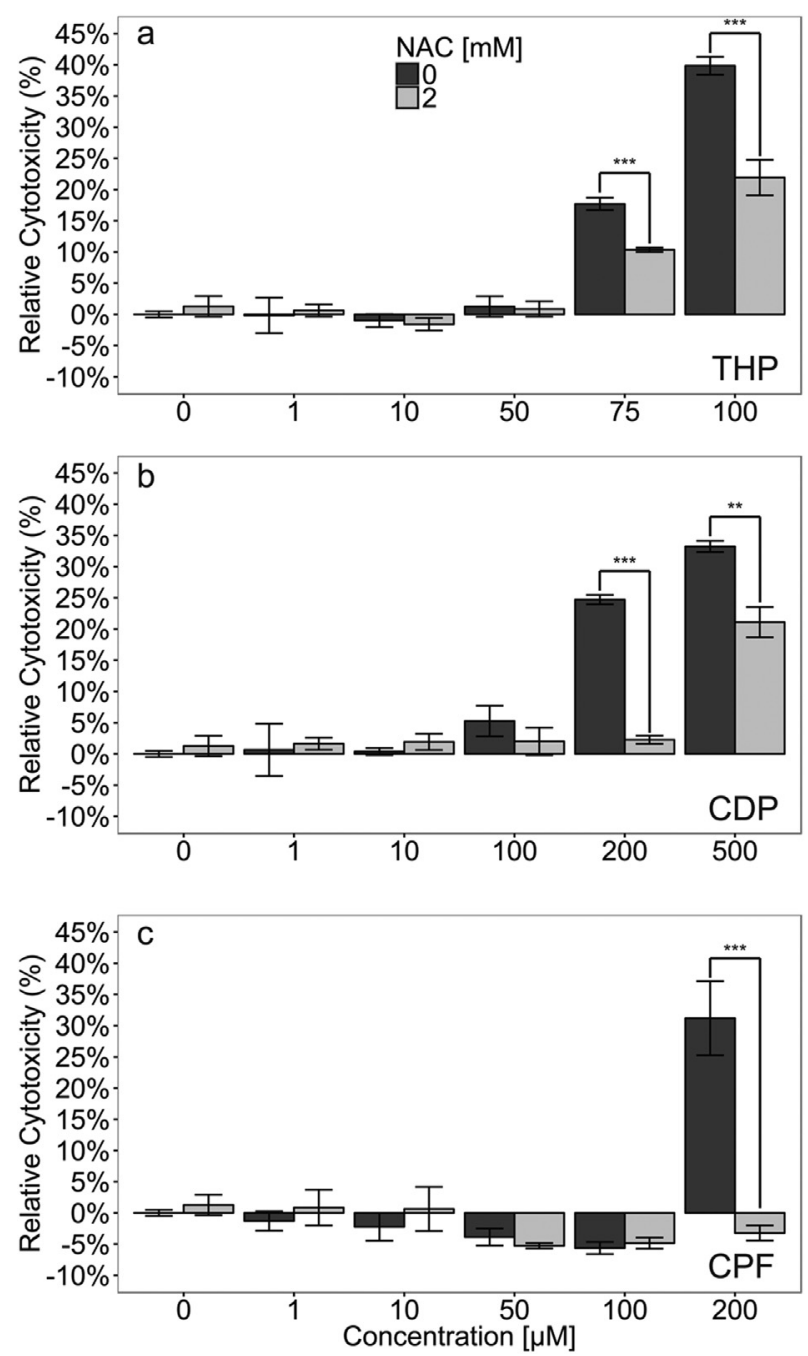

Fig. 9. Effects of THP, CDP and CPF on cytotoxicity by inhibit intracellular ROS production by using NAC. CHO-k1 cells were co-exposing $2 \mathrm{mM} \mathrm{NAC}$ and a range of concentration of THP (a), CDP (b), and CPF (c) for $3 \mathrm{~h}$. Cytotoxicity was measured by using CCK-8 cytotoxicity assay. The values presented are the mean \pm SEM of at least three independent experiments. ${ }^{*} p<0.05$; ${ }^{* *} p<0.01$; ${ }^{* * *} p<0.001$ (ANOVA) as compared to cells without NAC treatment.

among aryl-PFR-treated cells, those dead cells are mainly due to a loss of cell membrane integrity without obvious apoptotic characteristics (Fig. 5). Therefore, according to the results of the multiparameter HCS assay, clarification of the cell death mechanisms induced by representative alkyl- and aryl- PFRs is needed.

The rapid decrease in $\Delta \Psi$ suggests that mitochondria might be the one of the earliest targets affected by exposure to THP, CDP and CPF (Bova et al., 2005). These compounds are suspected to have a direct effect on the electron transport chain complexes or to possibly modulate the PTP (Bova et al., 2005). Additionally, a great deal of evidence supports that mitochondria are one of the primary targets of compound-induced cytotoxicity (Preston et al., 2001; Rasola and Bernardi, 2011). Considering that cell death is highly related to mitochondrial damage, the mechanisms of cell death induced by THP, CDP, and CPF need be identified. Previous studies have indicated that CPF can induce classical mitochondrialdependent apoptosis in PC12 cells (Lee et al., 2012). The results of this study confirmed that the cell death induced by THP and CPF in CHO-k1 cells occurs through a similar apoptotic pathway. This apoptotic pathway is triggered by the release of cytochrome $\mathrm{c}$ from 
the mitochondria, leading to sequential activation of caspase- 9 and 3. Caspase- 3 finally functions as the ultimate "executioner" of cell death (Stine and Brown, 2015). The mitochondrial permeability transition (MPT), in which the opening of the PTP leads to a dramatic increase in the permeability of the mitochondria, may allow mitochondrial constituents, including cytochrome c, ATP, $\mathrm{Ca}^{2+}$, etc., to leak out from mitochondria (Rasola and Bernardi, 2011). Importantly, ATP levels must be high enough to activate caspases in apoptosis. Otherwise, rapid depletion of ATP would make it impossible for cells to coordinate the apoptotic machinery and force them to turn to necrosis (Rasola and Bernardi, 2011; Richter et al., 1996). THP- and CPF-treated cells in this study successfully induced caspase- 9 and 3, and the cells seemed to have enough ATP to support apoptotic signalling. The elevation of intracellular calcium concentrations and ROS levels further supported that the apoptosis induced by THP and CPF was mediated by mitochondria (Rasola et al., 2010; Wang et al., 2008). The reduction of $\Delta \Psi$ indicated that the PTP might be persistently open in THP- and CPFtreated cells, such that the mitochondria no longer functioned as "firewalls" to control calcium homeostasis. Therefore, $\mathrm{Ca}^{2+}$ resting in the mitochondrial matrix was released, followed by cessation of oxidative phosphorylation and ROS production (Rasola and Bernardi, 2011). Further work should discern whether persistent opening of the PTP results directly from damage to mitochondria by THP and CPF or from $\mathrm{Ca}^{2+}$ overload in which mitochondria accumulate excessive $\mathrm{Ca}^{2+}$ from either the endoplasmic reticulum or opening of plasma membrane $\mathrm{Ca}^{2+}$ channels.

Some aryl-PFRs, such as TOCP, can induce the mitochondriamediated apoptotic pathway in adult hens (Zou et al., 2013). However, Carlson et al. found that $1 \mathrm{mM}$ TOCP could not only activate caspase- 3 but also be caused necrotic morphological changes in SH-SY5Y cells (Carlson et al., 2000). The cell death induced by TOCP seems to depend on an unusual mechanism. A similar conclusion from Karami-Mohajeri and Abdollahi (2013) also indicated that OPs can induce mitochondrial dysfunction and that there is more than one mechanism to explain the toxicity of OPs. In this study, CDP could inhibit cell viability, decrease $\Delta \Psi$, and lead to a failure of cell membrane integrity (Figs. 1, 2a, 5, 9b). All these results indicate that $3 \mathrm{~h}$ of exposure of $\mathrm{CHO}-\mathrm{k} 1$ cells to both CDP and THP could induce cell death. However, CDP treatment of cells maintained normal ATP and intracellular calcium levels and could not activate caspase- 3 and 9, cause chromatin condensation, or form apoptotic bodies (Fig. 7b and c, 8a, b). As a consequence, the cell death induced by CDP is different from traditional apoptosis (activation of caspase-3) or hydrogen peroxide $\left(\mathrm{H}_{2} \mathrm{O}_{2}\right)$-induced necrosis with MPT (ATP depletion) (Dixon et al., 2012). Thus, CDPinduced cell death might be a different type of necrosis. Necrosis can occur in a highly regulated and genetically controlled manner, and numerous examples of this process are emerging, including pyroptosis, necroptosis, parthanatos, ferroptosis, etc (Vanden et al., 2014). CDP-induced cell death seemed to be highly related to mitochondrial impairment, and this type of cell death did not cause chromatin condensation as in pyroptosis (Bergsbaken et al., 2009) or seem to be initiated through increasing cytoplasmic calcium as in necroptosis (Nomura et al., 2014). Two possibilities for the mode of cell death are parthanatos (David et al., 2009) and ferroptosis (Dixon et al., 2012). Both of these mechanisms cause cell death that is highly related to the mitochondria and not dependent on caspase. ROS can be produced in the processes of parthanatos and ferroptosis (David et al., 2009; Dixon et al., 2012), and in fact, ROS have been implicated in various forms of cell death. As a result, it is possible that apoptosis or another form of cell death could occur in "pure" parthanatos or ferroptosis (Reed and Pellecchia, 2012). Nevertheless, challenging work remains to discern the mechanisms of cell death that CDP or other PFRs induce.

\section{Conclusions}

In conclusion, mitochondrial impairment in cells has been observed upon treatment with most selected non-halogen PFRs except for those compounds with short alkyl chains. The results from the HCS assay indicated that PFRs with different structures are likely associated with distinct mechanisms of toxicity. THP was found to function via a similar pathway as CPF to induce apoptosis. CDP-induced cell death was distinct from classical necrosis. Further studies should be conducted to elucidate the cell death mechanisms of other PFRs and clarify the relationship between the cell death mechanism and the PFR structures. Finally, the results of the present work give insight into the toxicity of PFRs. The HCS analysis of mitochondrial toxicity has also been proven to be a promising in vitro strategy for evaluating the toxicity and identifying the mechanisms of environmental pollutants.

\section{Acknowledgements}

This research was financially supported by National Natural Science Foundation of China (21437006), Frontier Science Key Program of the Chinese Academy of Sciences (QYZDY-SSWDQC004), National Natural Science Foundation of China (51290283), Science and Technology Service Network Initiative (KFJ-SW-STS-171), and National High Technology Research and Development Program of China (2014AA06A506).

\section{Appendix A. Supplementary data}

Supplementary data related to this article can be found at http:// dx.doi.org/10.1016/j.envpol.2017.07.024.

\section{References}

Adams, C.L., Kutsyy, V., Coleman, D.A., Cong, G., Crompton, A.M., Elias, K.A., Oestreicher, D.R., Trautman, J.K., Vaisberg, E., 2006. [24]-Compound classification using image-based cellular phenotypes. Method Enzymol. 440-468.

Attene-Ramos, M.S., Huang, R., Sam, M., Witt, K.L., Richard, A., Tice, R.R., Simeonov, A., Austin, C.P., Xia, M., 2015. Profiling of the Tox21 chemical collection for mitochondrial function to identify compounds that acutely decrease mitochondrial membrane potential. Environ. Health Persp 123, 49.

Berghe, T.V., Linkermann, A., Jouanlanhouet, S., Walczak, H., Vandenabeele, P., 2014. Regulated necrosis: the expanding network of non-apoptotic cell death pathways. Nat. Rev. Mol. Cell Bio 15, 135-147.

Bergsbaken, T., Fink, S.L., Cookson, B.T., 2009. Pyroptosis: host cell death and inflammation. Nat. Rev. Microbiol. 7, 99-109.

Betts, K., 2008. Does a key PBDE break down in the environment? Environ. Sci. Technol. 42, 6781-6781.

Bova, M.P., Tam, D., McMahon, G., Mattson, M.N., 2005. Troglitazone induces a rapid drop of mitochondrial membrane potential in liver HepG2 cells. Toxicol. Lett. 155, 41-50.

Carlson, K., Jortner, B.S., Ehrich, M., 2000. Organophosphorus compound-induced apoptosis in SH-SY5Y human neuroblastoma cells. Toxicol. Appl. Pharm. 168, $102-113$.

Cox, P., Efthymiou, P., 2003. In: Union, O.J.E. (Ed.), Directive 2003/11/EC of the European Parliament and of the Council of February 62003 Amending for the 24th Time Council Directive 76/669/EEC Relating to Restrictions on the Marketing and Use of Certain Dangerous Substances and Preparations (Pentabromodiphenyl Ether, Octabromodiphenyl Ether), pp. 45-46.

Darzynkiewicz, Z., Juan, G., Li, X., Gorczyca, W., Murakami, T., Traganos, F., 1997. Cytometry in cell necrobiology: analysis of apoptosis and accidental cell death (necrosis). Cytometry 27, 1-20.

David, K.K., Andrabi, S.A., Dawson, T.M., Dawson, V.L., 2009. Parthanatos, a messenger of death. Front. Biosci. 14, 1116-1128.

Dishaw, L.V., Powers, C.M., Ryde, I.T., Roberts, S.C., Seidler, F.J., Slotkin, T.A., Stapleton, H.M., 2011. Is the PentaBDE replacement, tris (1,3-dichloro-2-propyl) phosphate (TDCPP), a developmental neurotoxicant? Studies in PC12 cells. Toxicol. Appl. Pharm. 256, 281-289.

Dixon, S.J., Lemberg, K.M., Lamprecht, M.R., Skouta, R., Zaitsev, E.M., Gleason, C.E., Patel, D.N., Bauer, A.J., Cantley, A.M., Yang, W.S., 2012. Ferroptosis: an irondependent form of fonapoptotic cell death. Cell 149, 1060-1072.

dos Santos, A.A., Naime, A.A., de Oliveira, J., Colle, D., dos Santos, D.B., Hort, M.A., Moreira, E.L.G., Suñol, C., de Bem, A.F., Farina, M., 2016. Long-term and low-dose malathion exposure causes cognitive impairment in adult mice: evidence of 
hippocampal mitochondrial dysfunction, astrogliosis and apoptotic events. Arch. Toxicol. 90, 647-660.

Du, Z., Wang, G., Gao, S., Wang, Z., 2015. Aryl organophosphate flame retardants induced cardiotoxicity during zebrafish embryogenesis: by disturbing expression of the transcriptional regulators. Aquat. Toxicol. 161, 25-32.

EPA, I., 2007. Report on Alternatives to the Flame Retardant DecaBDE: Evaluation of Toxicity, Availability, Affordability, and Fire Safety Issues. A Report to the Governor and the General Assembly.

EU, 2014. Directive 2014/79/EU. Appendix C of Annex II to Directive 2009/48/EC of the European Parliament and of the Council on Safty of Toys, as Regards TCEP, TCPP and TDCP. http://eur-lex.europa.eu/legal-content/EN/TXT/PDF/?uri\%3dOJ: JOL_2014_182_R_0012\%26from\%3dEN.

Ferrari, R., 1996. The role of mitochondria in ischemic heart disease. J. Cardiovasc Pharm. 28, 1-10.

Ferrer, E., Juan-García, A., Font, G., Ruiz, M., 2009. Reactive oxygen species induced by beauvericin, patulin and zearalenone in CHO-K1 cells. Toxicol Vitro 23, 1504-1509.

Hausherr, V., van Thriel, C., Krug, A., Leist, M., Schöbel, N., 2014. Impairment of glutamate signaling in mouse central nervous system neurons in vitro by tri-ocresyl phosphate (TOCP) at non-cytotoxic concentrations. Toxicol. Sci. 142 (1), $274-284$.

Hirsch, C., Striegl, B., Mathes, S., Adlhart, C., Edelmann, M., Bono, E., Gaan, S., Salmeia, K.A., Hoelting, L., Krebs, A., Nyffeler, J., Pape, R., Bürkle, A., Leist, M., Wick, P., Schildknecht, S., 2017. Multiparameter toxicity assessment of novel DOPO-derived organophosphorus flame retardants. Arch. Toxicol. 91, 407-425.

Horobin, R.W., Trapp, S., Weissig, V., 2007. Mitochondriotropics: a review of their mode of action, and their applications for drug and DNA delivery to mammalian mitochondria. J. Control Releas. 121, 125-136.

Hou, R., Xu, Y., Wang, Z., 2016. Review of OPFRs in animals and humans: absorption, bioaccumulation, metabolism, and internal exposure research. Chemosphere 153, 78-90.

Jiang, X., Wang, X., 2004. Cytochrome C-mediated apoptosis. Annu. Rev. Biochem. 73, 87-106.

Jin, Y., Chen, G., Fu, Z., 2015. Effects of TBEP on the induction of oxidative stress and endocrine disruption in Tm3 Leydig cells. Environ. Toxicol. 31, 1276.

Joshi, D.C., Bakowska, J.C., 2011. Determination of mitochondrial membrane potential and reactive oxygen species in live rat cortical neurons. J. Vis. Exp. e2704.

Karami-Mohajeri, S., Abdollahi, M., 2013. Mitochondrial dysfunction and organophosphorus compounds. Toxicol. Appl. Pharm. 270, 39-44.

Kluwe, W., Huff, J., Matthews, H., Irwin, R., Haseman, J., 1985. Comparative chronic toxicities and carcinogenic potentials of 2-ethylhexyl-containing compounds in rats and mice. Carcinogenesis 6, 1577-1583.

Lee, J.E., Park, J.H., Shin, I.C., Koh, H.C., 2012. Reactive oxygen species regulated mitochondria-mediated apoptosis in PC12 cells exposed to chlorpyrifos. Toxicol. Appl. Pharm. 263, 148-162.

Lin, M.T., Beal, M.F., 2006. Mitochondrial dysfunction and oxidative stress in neurodegenerative diseases. Nature 443, 787-795.

Meeker, J.D., Stapleton, H.M., 2010. House dust concentrations of organophosphate flame retardants in relation to hormone levels and semen quality parameters. Environ. Health Persp 118, 318.

Meyer, J.N., Leung, M.C., Rooney, J.P., Sendoel, A., Hengartner, M.O., Kisby, G.E., Bess, A.S., 2013. Mitochondria as a target of environmental toxicants. Toxicol. Sci. $134,1-17$.

Moser, V.C., Phillips, P.M., Hedge, J.M., McDaniel, K.L., 2015. Neurotoxicological and thyroid evaluations of rats developmentally exposed to tris (1, 3-dichloro-2propyl) phosphate (TDCIPP) and tris (2-chloro-2-ethyl) phosphate (TCEP). Neurotoxicol Teratol. 52, 236-247.

Nakagawa, Y., Moldeus, P., 1998. Mechanism of p-hydroxybenzoate ester-induced mitochondrial dysfunction and cytotoxicity in isolated rat hepatocytes. Biochem. Pharmacol. 55, 1907-1914.

NCBI, 2012. National Center for Biotechnology Information. PubChem BioAssay Database; $\operatorname{SID}=144210086, \mathrm{AID}=720635$, Source=Tox21. https://pubchem.ncbi. nlm.nih.gov/assay/bioactivity.html?sid=144210086.

NCBI, 2016a. National Center for Biotechnology Information. PubChem BioAssay Database; $\quad$ ID $=6537$, Source=HSDB. https://pubchem.ncbi.nlm.nih.gov/ compound $/ 6537$ \#section=Eye-Symptoms.

NCBI, 2016b. National Center for Biotechnology Information. PubChem BioAssay Database; CID=6537, Source=Tox21. https://pubchem.ncbi.nlm.nih.gov/assay/ bioactivity.html?cid=6537.

Nomura, M., Ueno, A., Saga, K., Fukuzawa, M., Kaneda, Y., 2014. Accumulation of cytosolic calcium induces necroptotic cell death in human neuroblastoma. Cancer Res. 74, 1056-1066.

Ott, M., Gogvadze, V., Orrenius, S., Zhivotovsky, B., 2007. Mitochondria, oxidative stress and cell death. Apoptosis 12, 913-922.

Preston, T.J., Abadi, A., Wilson, L., Singh, G., 2001. Mitochondrial contributions to cancer cell physiology: potential for drug development. Adv. Drug Deliv. Rev. 49, 45-61.

R Development Core Team, 2010. R: a Language and Environment for Statistical Computing. R Foundation for Statistical Computing, Vienna, Austria.

Rakotomalala, M., Wagner, S., Döring, M., 2010. Recent developments in halogen free flame retardants for epoxy resins for electrical and electronic applications.
Materials 3, 4300-4327.

Rasola, A., Bernardi, P., 2011. Mitochondrial permeability transition in $\mathrm{Ca}^{2+}$ dependent apoptosis and necrosis. Cell Calcium 50, 222-233.

Rasola, A., Sciacovelli, M., Pantic, B., Bernardi, P., 2010. Signal transduction to the permeability transition pore. FEBS Lett. 584, 1989-1996.

Reed, J.C., Pellecchia, M., 2012. Ironing out cell death mechanisms. Cell 149, 963-965.

Reemtsma, T., Weiss, S., Mueller, J., Petrovic, M., González, S., Barcelo, D., Ventura, F., Knepper, T.P., 2006. Polar pollutants entry into the water cycle by municipal wastewater: a european perspective. Environ. Sci. Technol. 40, 5451-5458.

Richter, C., Schweizer, M., Cossarizza, A., Franceschi, C., 1996. Control of apoptosis by the cellular ATP level. FEBS Lett. 378, 107-110.

Ritz, C., Streibig, J.C., 2005. Bioassay analysis using R. J. Stat. Softw. 12, 1-22.

Rodriguez, I., Calvo, F., Quintana, J., Rubí, E., Rodil, R., Cela, R., 2006. Suitability of solid-phase microextraction for the determination of organophosphate flame retardants and plasticizers in water samples. J. Chromatogr. A 1108, 158-165.

Sailem, H., Sero, J.E., Bakal, C., 2015. Visualizing cellular imaging data using PhenoPlot. Nat. Commun. 6, 5825-5825.

Shaughnessy, D.T., McAllister, K., Worth, L., Haugen, A.C., Meyer, J.N., Domann, F.E., Van Houten, B., Mostoslavsky, R., Bultman, S.J., Baccarelli, A.A., 2014. Mitochondria, energetics, epigenetics, and cellular responses to stress. Environ. Health Persp 122, 1271.

Stine, K.E., Brown, T.M., 2015. Principles of Toxicology, third ed. Crc Press.

Stone, S.J., Vance, J.E., 2000. Phosphatidylserine synthase-1 and-2 are localized to mitochondria-associated membranes. J. Biol. Chem. 275, 34534-34540.

Sun, S.Y., 2010. N-acetylcysteine, reactive oxygen species and beyond. Cancer Biol. Ther. 9, 109-110.

Takigawa, K., Sasaki, U., Suda, S., 2001. Fluid Composition Comprising HFC Refrigerant and Alkylbenzene-based Refrigerator Oil. Google Patents.

Tanaka, M., Bateman, R., Rauh, D., Vaisberg, E., Ramachandani, S., Zhang, C., Hansen, K.C., Burlingame, A.L., Trautman, J.K., Shokat, K.M., 2005. An unbiased cell morphology-based screen for new, biologically active small molecules. PLoS Biol. 3, e128.

Terry, A.V., 2012. Functional consequences of repeated organophosphate exposure: potential non-cholinergic mechanisms. Pharmacol. Ther. 134, 355-365.

Tirmenstein, M.A., Hu, C., Gales, T.L., Maleeff, B.E., Narayanan, P., Kurali, E., Hart, T.K. Thomas, H.C., Schwartz, L.W., 2002. Effects of troglitazone on HepG2 viability and mitochondrial function. Toxicol. Sci. 69, 131-138.

Tolosa, L., Carmona, A., Castell, J.V., Gómez-Lechón, M.J., Donato, M.T., 2015. Highcontent screening of drug-induced mitochondrial impairment in hepatic cells: effects of statins. Arch. Toxicol. 89, 1847-1860.

van der Veen, I., de Boer, J., 2012. Phosphorus flame retardants: properties, production, environmental occurrence, toxicity and analysis. Chemosphere 88 , 1119-1153.

Vanden, B.T., Linkermann, A., Jouanlanhouet, S., Walczak, H., Vandenabeele, P., 2014. Regulated necrosis: the expanding network of non-apoptotic cell death pathways. Nat. Rev. Mol. Cell Bio 15, 135-147.

Wallace, K.B., Starkov, A.A., 2003. Mitochondrial targets of drug toxicity. Annu. Rev. Pharmacol. 40, 353-388.

Wang, H., Joseph, J.A., 1999. Quantifying cellular oxidative stress by dichlorofluorescein assay using microplate reader. Free Radic. Bio Med. 27, 612-616.

Wang, W., Fang, H., Groom, L., Cheng, A., Zhang, W., Liu, J., Wang, X., Li, K., Han, P., Zheng, M., 2008. Superoxide flashes in single mitochondria. Cell 134, 279-290.

Westerink, W.M., Schirris, T.J., Horbach, G.J., Schoonen, W.G., 2011. Development and validation of a high-content screening in vitro micronucleus assay in CHOk1 and HepG2 cells. Mutat. Res-Gen Tox En. 724, 7-21.

Whitaker, R.M., Corum, D.G., Beeson, C.C., Schnellmann, R.G., 2016. Mitochondrial biogenesis as a pharmacological target: a new approach to acute and chronic diseases. Annu. Rev. Pharmacol. 56, 229-249.

Wickham, H., 2016. ggplot2: Elegant Graphics for Data Analysis. Springer.

Wolpaw, A.J., Shimada, K., Skouta, R., Welsch, M., Akavia, U.D., Peer, D., Shaik, F., Bulinski, J.C., Stockwell, B.R., 2011. Modulatory profiling identifies mechanisms of small molecule-induced cell death. P Natl. Acad. Sci. U. S. A. 108, 16151-16152.

Xie, Y., Hou, W., Song, X., Yu, Y., Huang, J., Sun, X.W., Kang, R., Tang, D., 2016. Ferroptosis: process and function. Cell Death Differ. 23, 369-379.

Yamada, S., Kubo, Y., Yamazaki, D., Sekino, Y., Kanda, Y., 2017. Chlorpyrifos inhibits neural induction via Mfn1-mediated mitochondrial dysfunction in human induced pluripotent stem cells. Sci. REP-UK 7, 40925.

Ye, Y., Weiwei, J., Na, L., Mei, M., Kaifeng, R., Zijian, W., 2014. Application of the SOS/ umu test and high-content in vitro micronucleus test to determine genotoxicity and cytotoxicity of nine benzothiazoles. J. Appl. Toxicol. 34, 1400-1408.

Yuan, L., Li, J., Zha, J., Wang, Z., 2016. Targeting neurotrophic factors and their receptors, but not cholinesterase or neurotransmitter, in the neurotoxicity of TDCPP in Chinese rare minnow adults (Gobiocypris rarus). Environ. Pollut. 208, 670-677.

Zhou, D., Li, W., Tan, C., Zuo, X., Huang, Y., 2008. Cresyl diphenyl phosphate as flame retardant additive for lithium-ion batteries. J. Power Sources 184, 589-592.

Zou, C., Kou, R., Gao, Y., Xie, K., Song, F., 2013. Activation of mitochondria-mediated apoptotic pathway in tri-ortho-cresyl phosphate-induced delayed neuropathy. Neurochem. Int. 62, 965-972. 